International Journal of Current Advanced Research

ISSN: O: 2319-6475, ISSN: P: 2319 - 6505, Impact Factor: SJIF: 5.995

Available Online at www.journalijcar.org

Volume 6; Issue 5; May 2017; Page No. 3686-3688

DOI: http://dx.doi.org/10.24327/ijcar.2017.3688.0347

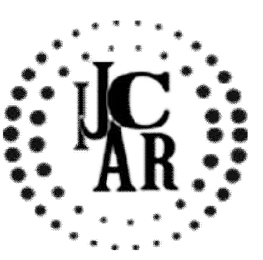

Case Report

\title{
MUCINOUS CYSTADENOMA OF THE APPENDIX - A RARE CASE REPORT
}

\section{Radhika Yajaman Gurumurthy*., Nadig Siddharth Shankar., Mohan Raj C.S and Nadig Sriram}

Consultant Pathologists, Bhagavan Pathology Laboratory, \#1116, 5TH CROSS, 1503, Srirampet, Vinoba Road, Mysore - 570001

\section{A R T I C L E I N F O}

\section{Article History:}

Received $16^{\text {th }}$ February, 2017

Received in revised form $12^{\text {th }}$ March, 2017

Accepted $5^{\text {th }}$ April, 2017

Published online $28^{\text {th }}$ May, 2017

\section{Key words:}

Mucinous cystadenoma, Mucocele, Appendix.

\begin{abstract}
A B S T R A C T
Mucinous cystadenoma is rare but is the most common benign appendiceal tumor. Although a benign tumor, mucinous cystadenoma can be a devastating condition if not treated optimally, as it can lead to pseudomyxoma peritonei. However, with appropriate treatment this tumor has excellent prognosis. Thus accurate diagnosis and optimal treatment is very essential in case of this tumor. In this case report we describe the clinical and histopathological features of appendiceal mucinous cystadenoma.
\end{abstract}

Copyright $₫ 2017$ Radhika Yajaman Gurumurthy. This is an open access article distributed under the Creative Commons Attribution License, which permits unrestricted use, distribution, and reproduction in any medium, provided the original work is properly cited.

\section{INTRODUCTION}

Mucinous cystadenoma is rare but is the most common benign appendiceal tumor. ${ }^{1}$ Although a benign tumor, mucinous cystadenoma can be a devastating condition if not treated optimally, as it can lead to pseudomyxoma peritonei. ${ }^{2}$ Since this tumor has highly variable clinical presentation, it is important to consider the diagnosis of mucinous cystadenoma in cases of cystic lesions of right lower quadrant of the abdomen. Here, we describe a case of mucinous cystadenoma presenting as appendicitis and present a brief review of literature.

\section{Case Report}

A 55 year old lady came with a complaint of chronic lower abdominal pain which had aggrevated suddenly. On examination there was right lower quadrant tenderness without peritoneal signs. Ultrasonography of the abdomen revealed a cystic mass. On exploratory laparotomy, the cystic mass turned out to be mucocele of the appendix. Since there was no caecal involvement only appendecectomy was performed.

Surgical specimen consisted of appendix having a thinned out wall and a dialated lumen filled with mucoid material. On microscopy, the wall of the appendix was lined by crowded tall columnar adenomatous epithelium with basally located, hyperchromatic, pseudostratified nuclei and apical mucin. Epithelial cells exhibited mild degree of dysplasia. The lumen was filled with mucoid material. The case was signed out as mucinous cystadenoma of the appendix.

\footnotetext{
*Corresponding author: Radhika Yajaman Gurumurthy Consultant Pathologists, Bhagavan Pathology Laboratory, \#1116, 5TH CROSS, 1503, Srirampet,

Vinoba Road, Mysore - 570001
}

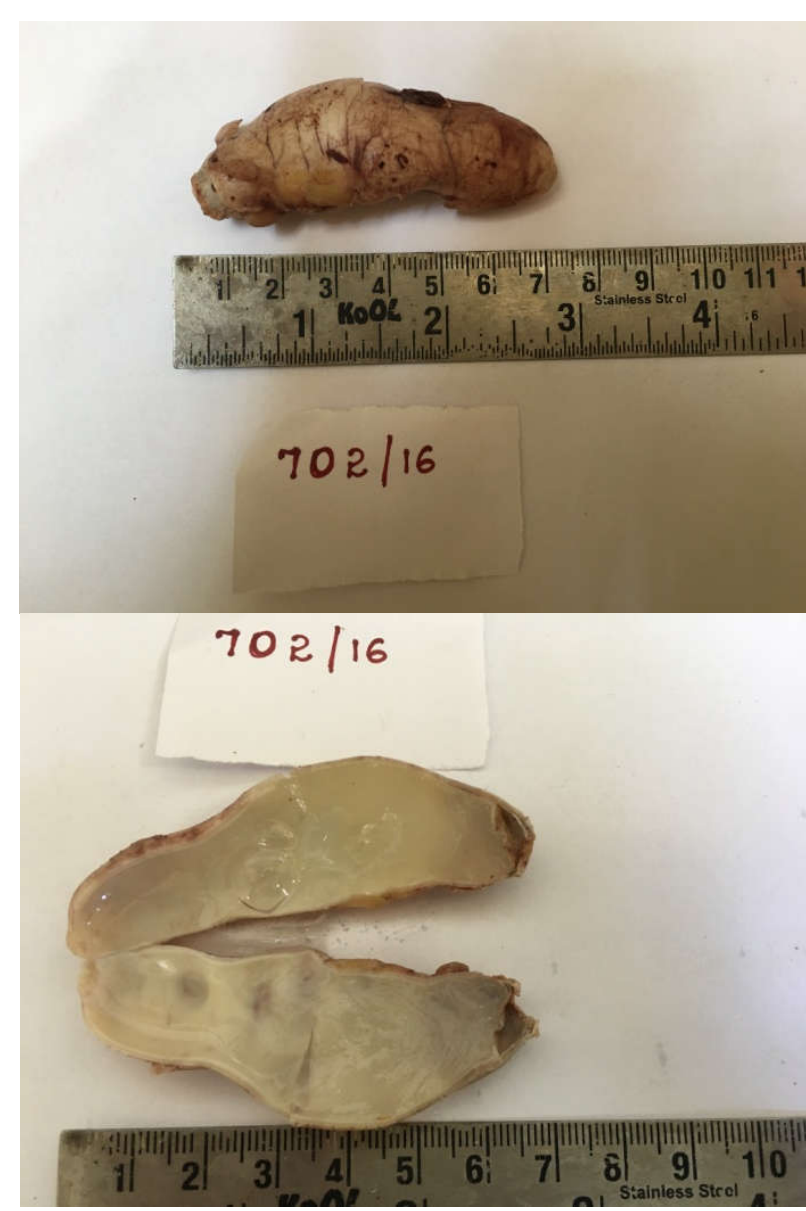

Figure 1 \& 2 Surgical Specimen: Appendix With Thinned Out Wall And Dialated Lumen Filled With Mucoid Material. 


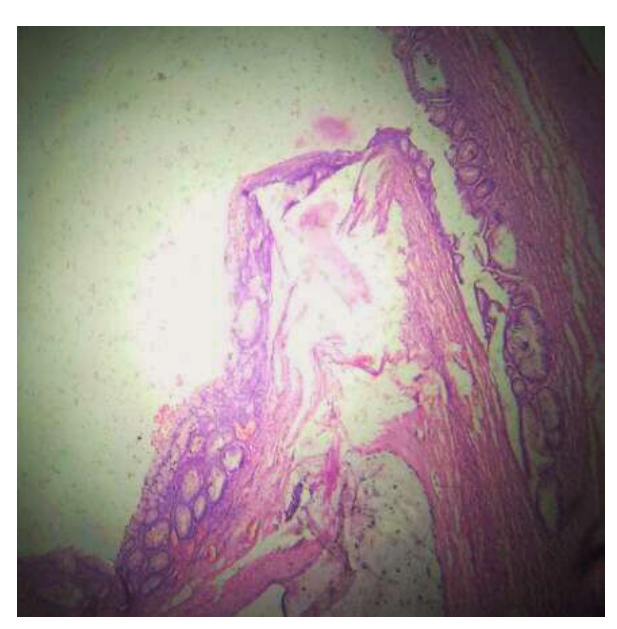

Figure 3 Microscopy: Thinned Out Wall of Appendix Lined By Mucous Glands And Tall Columnar Epithelium With Apical Mucin
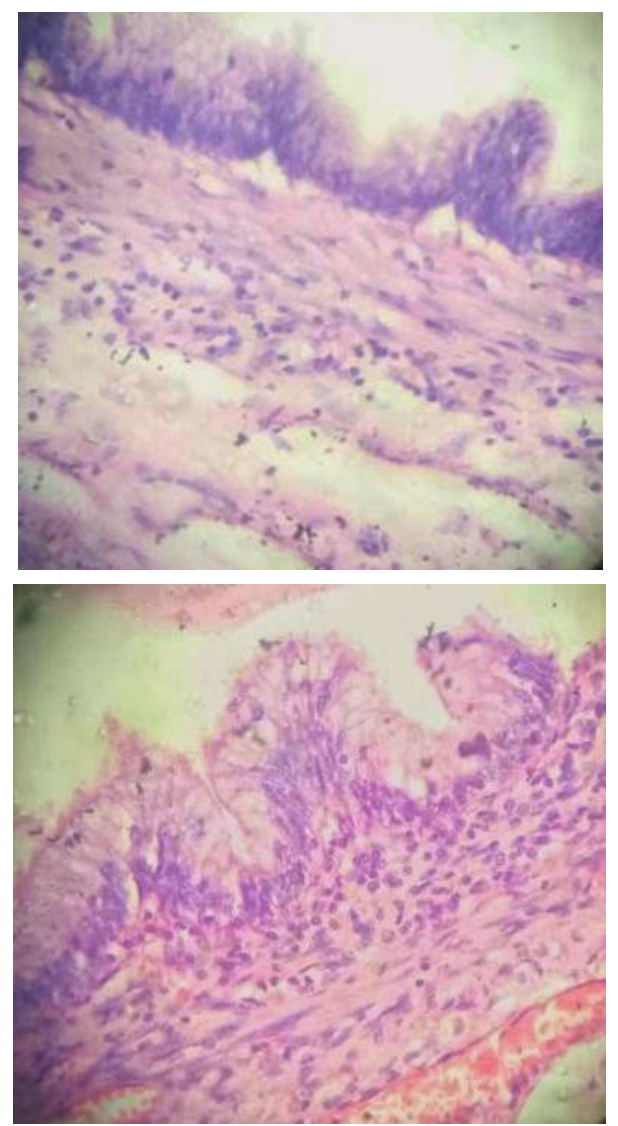

Figure 4 \& 5 Microscopy: Wall Of The Appendix Lined By Pseudostratified Tall Columnar Epithelium With Basally Located, Elongated, Hyperchromatic Nuclei And Cytoplasmic Apical Mucin.

\section{DISCUSSION}

Appendiceal tumors are rare accounting for only $0.4 \%$ of gastrointestinal tumors. ${ }^{3}$ Appendiceal mucocele, which was first described by Rokitansky, represents a dialatation of appendix from the intraluminal accumulation of mucoid material. The incidence of mucocele varies between $0.2-0.7 \%$ among appendicectomy specimens. Mucocele is the second most common type of appendiceal tumor after carcinoid. The causes of mucocele include retention cyst, mucosal hyperplasia, mucinous cystadenoma and mucinous cystadenocarcinoma. Mucinous cystadenoma is the most common cause of mucocele accounting for about $63-84 \%$ cases. ${ }^{4}$ It develops as a result of proliferation of mucin secreting epithelium in an occluded appendix. ${ }^{5}$

Mucinous cystadenoma occurs more commonly in women and in patients aged more than 50 years. $^{2}$ The clinical presentation of appendiceal mucinous cystadenoma is highly variable. $^{4}$ It may present as incidental finding, palpable abdominal mass or chronic right lower abdominal pain. ${ }^{1,4,6,7}$ Rare cases of mucinous cystadenoma presenting with bleeding, intussusceptions, umbilical hernia, volvulus, ureteral obstruction and hematuria have also been reported in literature. ${ }^{8,9,10,3,7}$ Synchronous cases of mucinous cystadenoma with colon cancer have been described with an incidence of upto $20 \%{ }^{9}$

Mucinous cystadenomas are associated with perforation in $20 \%$ of the cases. ${ }^{6}$ Pseudomyxoma peritonei is a potentially devastating complication of mucinous cystadenoma which occurs due to rupture of mucocele. ${ }^{4}$ It may either occur due to spontaneous rupture or spillage of contents into peritoneum during surgery. ${ }^{11}$ Other complications include invasion into adjacent organs, recurrence and torsion. ${ }^{12}$

$\mathrm{CT}$ is the gold standard for radiological diagnosis. It is more informative than MRI and USG. ${ }^{4}$ However it is challenging to diagnose this condition pre-operatively as smaller lesions are often asymptomatic and larger lesions mimic normal or dialated small bowel on imaging studies. ${ }^{2}$ Tumor marker studies like CEA levels can be useful in the diagnosis. ${ }^{13}$

Intra-operative frozen section is usually preferable in cases of appendiceal tumors, because it is extremely difficult to diagnose cystic appendiceal lesions pre-operatively and it is essential to distinguish between mucinous cystadenoma and cystadenocarcinoma as the latter needs an extensive procedure for optimum management. ${ }^{14}$

Mucinous cystadenomas show marked distention of lumen upto $6 \mathrm{~cm} .{ }^{4}$ On histopathology, they show epithelial villous adenomatous changes with some degree of epithelial atypia. ${ }^{15}$ It is now widely accepted that mucinous cystadenoma is the appendiceal counterpart of villous adenomas occurring elsewhere in the intestine. ${ }^{16}$ Mucinous cystadenomas generally tend to be low grade, with circumferential involvement. Progressive mucocele formation results in thinning of the wall due to pressure atrophy and progressive fibrosis. ${ }^{17}$

Surgical resection is the main modality of treatment of mucinous cystadenoma. The extent of surgery depends on thickness, dimension and involvement of caecal base by the tumor. ${ }^{4}$ In cases of mucinous cystadenomas without caecal involvement, resection of appendix is performed, followed by collection and cytological examination of peritoneal fluid and careful inspection of the base of the appendix. ${ }^{11}$ Cecectomy is performed in cases of mucinous cystadenomas having thick base, involving caecum, patients with a positive margin at the base of the appendix or with positive lymph node. ${ }^{4,11}$ Laparoscopic approach has also been described for the management of appendiceal mucoceles in few recent studies. $18,19,20,21$

The prognosis of mucinous cystadenoma is excellent. The five year survival rate is approximately $100 \%{ }^{22}$ 


\section{CONCLUSION}

Mucinous cystadenoma remains a diagnosis that is rarely considered before elective surgery. However, accurate diagnosis is very essential to ensure optimal treatment and prevent complications like pseudomyxoma peritonei. Thus the diagnosis of appendiceal mucinous cystadenoma should always be kept in mind in cases of cystic lesions of right lower quadrant of the abdomen.

\section{References}

1. Velusamy A, Saw S, Gossage J et al. Combined adenocarcinoid and mucinous cystadenoma of the appendix: A case report. Journal of Medical Case Reports 2009; 28(3).

2. Michetti C P. Mucinous cystadenoma of the appendix. JSM Gen Surg Cases Images 2016; 1(3):1011.

3. Jha NK, Sinha DK, Anand A et al. Mucinous cystadenoma of the appendix with enterocutaneous fistula: A therapeutic dilemma. Gastroenterology Report 2015; 3:86-9.

4. Reznichenko A A. Giant Mucinous Cystadenoma of the Appendix With Low Grade Dysplasia Presented as Acute Appendicitis: A Case Report and Literature Review. J Curr Surg 2015; 5(1):146-50.

5. Dhage-Ivatury S, Sugarbaker PH.Update on the surgical approach to mucocele of the appendix. $J \mathrm{Am}$ Coll Surg 2006; 202:680-4.

6. Tsitouridis I, Kouklakis G, Kalambakas A et al. Giant appendiceal mucoceles of cystadenomas type: CT and MRI evaluation. Report of three cases and review of literature. Annals of Gastroenterology 2002, 15(1):53-7.

7. Chong SJ, Chan MYP. Mucinous Cystadenoma of the Appendix-An Unusual Cause of Intestinal Obstruction. Ann Acad Med Singapore 2001; 30:206-7.

8. Ren B, Meng X, Chao Z et al. Mucinous cystadenoma of the appendix presenting as an umbilical hernia: A case report. Oncology Letters 2016; 11:4200-2.

9. Zagrodnik DF, Rose DM. Mucinous Cystadenoma of the Appendix: Diagnosis, Surgical Management, and Follow-up. Current Surgery 2003; 60(3): 341-3.

10. Khan MR, Ahmed R, Saleem T. Intricacies in the surgical management of appendiceal mucinous cystadenoma: A case report and review of the literature. Journal of Medical Case Reports 2010; 4:129.
11. Grover AS, Singh A, Singh G et al. Appendiceal mucinous cystadenoma- An incidental finding. Sch $J$ Med Case Rep 2016; 4(7):534-6.

12. Hebert JJ, Pickhardt PJ. MDCT diagnosis of an appendiceal mucocele with acute torsion. AJR Am J Roentgenol 2007; 189:W4-6.

13. McFarlane MEC, Plummer JM, Bonadie K. Mucinous cystadenoma of the appendix presenting with an elevated carcinoembryonic antigen (CEA): Report of two cases and review of the literature. International Journal of Surgery Case Reports 2013; 4:886- 8.

14. Choudary P. Mucinous Cystadenoma of the Appendix: A Diagnostic Dilemma. Journal of Surgical Academia 2014; 4(1):60-2.

15. Alese OB, Irabor DO. Mucinous cystadenoma of the appendix: AF case report. African Health Sciences 2010; 10 (1): 99 -100.

16. Dellaportas D, Vlahos NF, Polymeneas G et al. Collision Tumor of the Appendix: Mucinous Cystadenoma and Carcinoid.A Case Report. Chirurgia 2014; 109(6): 843-5.

17. Persaud T, Swan N, Torregianni WC. Giant Mucinous Cystadenoma of the Appendix. RadioGraphics 2007; 27:553-7.

18. Lau H, Yuen WK, Loong $\mathrm{F}$ et al. Laparoscopic resection of an appendiceal mucocele. Surgical Laparoscopy, Endoscopy and Percutaneous Techniques 2002; 12(5):367-70.

19. Miraliakbari R, Chapman III WHH. Laparoscopic treatment of an appendiceal mucocele. Journal of Laparoendoscopic \& Advanced Surgical Techniques 1999; 9(2):159-63.

20. Chiu CC, Wei PL, Huang MT et al. Laparoscopic resection of appendiceal mucinous cystadenoma. $J$ Laparoendosc Adv Surg Tech A. 2005; 15:325-8.

21. Acıkgoz A, Öztürk H, Çavuş H. Laparoscopic Retroperitoneal resection of mucinous cystadenoma of appendix. Robotics, Lap and Endosurg 2016; 2(2): 100-4.

22. Yeh CC, Li YK, Chang JL et al. Synchronous mucinous cystadenoma of the appendix in a patient with colon cancer. Transl Cancer Res 2016; 5(6):88791.

\section{How to cite this article:}

Radhika Yajaman Gurumurthy et al (2017) ' Mucinous Cystadenoma Of The Appendix - A Rare Case Report', International Journal of Current Advanced Research, 06(05), pp. 3686-3688.

DOI: http://dx.doi.org/10.24327/ijcar.2017.3688.0347 